serie Upstream incentives to encourage downstream competition in a vertically separated industry

WP-AD 2015-04 Joel Sandonís and J avier M. López-Cuñat 
Los documentos de trabajo del Ivie ofrecen un avance de los resultados de las investigaciones económicas en curso, con objeto de generar un proceso de discusión previo a su remisión a las revistas científicas. Al publicar este documento de trabajo, el Ivie no asume responsabilidad sobre su contenido.

Ivie working papers offer in advance the results of economic research under way in order to encourage a discussion process before sending them to scientific journals for their final publication. Ivie's decision to publish this working paper does not imply any responsibility for its content.

La Serie AD es continuadora de la labor iniciada por el Departamento de Fundamentos de Análisis Económico de la Universidad de Alicante en su colección "A DISCUSIÓN" y difunde trabajos de marcado contenido teórico. Esta serie es coordinada por Carmen Herrero.

The AD series, coordinated by Carmen Herrero, is a continuation of the work initiated by the Department of Economic Analysis of the Universidad de Alicante in its collection "A DISCUSIÓN", providing and distributing papers marked by their theoretical content.

Todos los documentos de trabajo están disponibles de forma gratuita en la web del Ivie http://www.ivie.es, así como las instrucciones para los autores que desean publicar en nuestras series.

Working papers can be downloaded free of charge from the Ivie website http://www.ivie.es, as well as the instructions for authors who are interested in publishing in our series.

Versión: abril 2015 / Version: April 2015

Edita / Published by:

Instituto Valenciano de Investigaciones Económicas, S.A.

C/ Guardia Civil, 22 esc. $21^{\circ}$ - 46020 Valencia (Spain) 
WP-AD 2015-04

\title{
Upstream incentives to encourage downstream competition in a vertically separated industry*
}

\author{
Joel Sandonís and Javier M. López-Cuñat ${ }^{* *}$
}

\begin{abstract}
We show in this paper that a dominant supplier, under observable two-part tariff contracts and an alternative, less efficient supply of the input, could benefit from more intense competition downstream provided that it has strong enough market power upstream. This implies that the incentives of upstream suppliers to foreclose downstream firms are less important than the previous literature had suggested. In fact, we find that the result also holds under observable linear contracts when we consider free entry in the downstream market.
\end{abstract}

Keywords: dominant upstream firm, downstream competition, wholesale price, two-part tariff contracts.

JEL classification numbers: L11, L13, L14.

\footnotetext{
* We thank an anonymous referee for very helpful comments. Support from Ministerio de Economía y Competitividad under project ECO2012-34928, Generalitat Valenciana under grant PROMETEO/2013/037 and the Ivie are gratefully acknowledged.

** J. Sandonís and J.M. López-Cuñat: University of Alicante, Economics Department. Corresponding author: J. Sandonis, e-mail: sandonis@ua.es.
} 


\section{Introduction}

This paper seeks to analyze the relationship between upstream profits and downstream competition, which is a crucial factor affecting the incentives of firms for vertical integration and/or market foreclosure (see Rey and Tirole's (2007) survey). Consider an upstream monopolist selling an input to a downstream Cournot oligopolistic industry through observable two-part tariff contracts. As it is well known in the literature (see for example Mathewson and Winter (1984) and Perry and Porter (1989)), the upstream firm can fully exert its market power and obtain the full monopoly profit regardless of the number of downstream rivals. However, upstream firms are rarely pure monopolists. They have very often to compete with other input suppliers. Suppose that a dominant upstream firm faces an alternative, less efficient supplier of the input. In this case, the dominant supplier cannot, in general, extract the full monopoly profit because downstream firms then have an outside option, that is, they can buy instead from the alternative supplier. Therefore, what the dominant supplier aims to maximize in this setting is total industry profits minus the (sum of) outside options of downstream firms. On the one hand, maximizing total industry profit seeks a high wholesale price, while on the other hand, minimizing outside options requires a low wholesale price. In other words, by increasing the wholesale price, the upstream firm increases the total size of the pie to be shared in the market; by reducing the wholesale price, however, it increases the share obtained of a lower pie. The optimal contract trades-off these two opposing incentives.

What is the effect of an increase in the number of downstream firms both on the optimal contract and on the dominant supplier's profit? Concerning the former effect, it is intuitive that there is a positive relationship between the number of downstream firms and the optimal wholesale price (see also Faulí-Oller and Sandonís (2014)). The reason is that, as the number 
of downstream firms increases, the dominant supplier optimally sells the input to all the new firms and, by increasing the wholesale price, it controls the level of downstream competition. As regards the effect on the dominant supplier's profits, we show that when the cost dissadvantage of the alternative supplier is large enough, tougher competition downstream is profitable for the dominant supplier. This result is reversed when the cost disadvantage of the alternative supplier is small. The intuition for the result is as follows: on the one hand, when we add an additional downstream firm, total industry profits reduce, which hurts the upstream firm's profits. On the other hand, with respect to the effect on the sum of downstream firms' outside options, there is a direct positive effect, but there is also an indirect negative effect as, with more fierce downstream competition, the cost disadvantage of sourcing from the alternative supplier is magnified (individual outside options reduce); and this negative effect is more significant when the cost disadvantage of the alternative supplier is larger. Consequently, when the alternative supplier is sufficiently less efficient than the dominant supplier, the effect on the sum of the outside options becomes negative and large, and this effect is shown to more than compensate the drop in total industry profits, leading to our result.

We also discuss in the paper whether the previous result is robust to the assumptions of our model, in particular the ones concerning the type of contract (linear vs. two-part tariffs) and the existence or not of upstream competition. We conclude that it is indeed a more general result that holds, for example, in a setting where the upstream firm uses linear wholesale prices no matter whether or not there is an alternative supplier. The reason is that under linear contracts, the optimal wholesale price is constant in the number of downstream firms and thus, the wholesale revenues of the dominant/monopolistic supplier are increasing in the number of downstream competitors simply because total output (and total input demand) increases with the number of firms in the market, which also reduces the double marginalization problem. 
Finally, we show that our result can also be extended to a setting where there is costly free entry in the downstream market. In this case, the dominant supplier would find it profitable to subsidize entry by reducing the wholesale price (compared with the one we obtained in the setting without entry) in order to encourage the entry of new firms in the downstream market.

To the best of our knowledge, there are only two other papers in the literature that address the same question, namely, Caprice (2005) and Chemla (2003). They both consider, however, the case of secret contracts. The present paper is thus the first in the literature dealing with this issue in the context of observable contracts. Caprice (2005) considers the case of secret two-part tariff contracts. A well known opportunistic problem arises in the case of secret contracts: once the upstream firm has contracted with a downstream firm, it has an incentive to renegotiate other contracts in order to increase its profits at that firm's expense. ${ }^{1}$ This opportunistic problem reduces the upstream firm's profits as downstream firms, anticipating the lack of commitment of the input producer are willing to pay less for the input. For example, under the so called passive beliefs and Cournot competition downstream, the equilibrium wholesale price equals the marginal cost of producing the input and the fixed fee is used to extract the entire downstream firm's profits. In this setting, it is very intuitive that the upstream firm's profits are decreasing in the number of downstream competitors simply because downstream competition erodes industry profits. However, as Caprice (2005) shows, this negative relationship could turn out to be positive if we add an alternative less efficient supplier of the input. In this new framework, an interesting trade-off arises as the dominant supplier then wants the outside option of downstream firms to be as small as possible, and this outside option is decreasing in the number of downstream competitors. This author obtains that if the alternative supplier is efficient enough and up to a threshold value for the number of downstream firms, the profit-reducing effect is offset by this

\footnotetext{
${ }^{1}$ This well known commitment problem faced by the supplier under secret contracts is due to Hart and Tirole (1990), and was further analyzed among others, by O'Brien and Shaffer (1992) and McAfee and Schwartz (1994).
} 
new rent-shifting effect and, as a result, the dominant upstream firm's profit increases with the number of downstream firms.

It is interesting to note that whereas in Caprice's (2005) setting with secret contracts, the upstream profits increase with $n$ when the alternative supplier is efficient enough, in our context with observable contracts, the result is obtained for an inefficient enough alternative supplier. The reason for the discrepancy between both papers must be in the role played by the wholesale price in both models. Whereas under secret two-part tariff contracts and due to the opportunistic problem, the wholesale price equals the marginal production cost and does not depend either on $n$ or on the efficiency of the alternative supplier, in our setting with observable contracts, the wholesale price increases with $n$ and it increases more the less efficient the alternative supplier is.

Chemla (2003) also investigates the relationship between upstream market profits and the degree of downstream competition in a related framework with secret contracts, specific upstream costs and bargaining between upstream and downstream firms. When both an upstream firm has convex costs and downstream firms have non negligible bargaining power, there is a range over which the dominant upstream firm's profit increases with the number of downstream firms. The dominant supplier then faces a trade off between a negative rent dissipation effect and a positive bargaining effect of increased downstream competition. When downstream firms have high bargaining power, the latter effect is shown to dominate.

The rest of the article is organized as follows. In the next section, we analyze the model with an alternative supplier and observable two-part tariff contracts. Section 3 discusses the robustness of the results in the case of linear wholesale prices with and without an alternative supplier and likewise considers the possibility of entry in the downstream market. Finally, Section 4 concludes. 


\section{Observable two-part tariff contracts with an alternative sup- ply.}

Consider a dominant input supplier that produces an input at a constant marginal cost $c$. The dominant firm faces a less efficient second source supplier, that we model as a competitive fringe and sells the input at a cost $c^{\prime}$, with $c<c^{\prime}$. A number $n$ of downstream firms transform this input into a final homogenous good on a one-to-one basis, without additional costs. ${ }^{2}$ The inverse demand for the final good is given by $P=a-Q$, where $Q$ is the total amount produced, $a>c^{\prime}>c$ and downstream firms compete in quantities.

The game is modelled according to the following timing: first, the dominant supplier offers an observable two-part tariff contract $(F, w)$ to downstream firms, where $F$ specifies a non-negative fixed fee and $w$ a linear wholesale price. Second, downstream firms decide whether or not to accept the contract. The ones that accept, pay $F$ to the upstream firm. Finally, they compete à la Cournot, with the marginal costs inherited from the second stage. In particular, the firms that accept the contract have a marginal cost $w$ and the firms that do not accept the contract buy the input from the alternative supply and have a marginal cost $c^{\prime}$.

Assume that $k$ firms have accepted a supply contract $(F, w)$. Firms that have not accepted the contract produce at the third stage in equilibrium:

$$
q_{N}(k, w)= \begin{cases}\frac{a-c^{\prime}(k+1)+w k}{n+1} & \text { if } \quad w>\frac{-a+c^{\prime}(k+1)}{k} \\ 0 & \text { otherwise. }\end{cases}
$$

\footnotetext{
${ }^{2}$ This would be equivalent to considering that the dominant input supplier is a final good manufacturer that distributes and sells the final good through a set of $n$ retailers.
} 
On the other hand, the firms that accept the contract produce in equilibrium:

$$
q(k, w)= \begin{cases}\frac{a+c^{\prime}(n-k)-w(n-k+1)}{n+1} & \text { if } \quad w>\frac{-a+c^{\prime}(k+1)}{k} \\ \frac{a-w}{k+1} & \text { otherwise. }\end{cases}
$$

Observe that, if $w$ is sufficiently low, the firms that do not accept the contract are driven out of the market. In that case, the firms that accept the contract produce the Cournot output when there are only $k$ active firms in the market. Profits of non-accepting and accepting firms are given, respectively, by $\Pi_{N}(k, w)=\left(q_{N}(k, w)\right)^{2}$ and $\Pi(k, w)=(q(k, w))^{2}$.

In the second stage, downstream firms accept the contract offered by the upstream firm whenever $F \leq \Pi(k, w)-\Pi_{N}(k-1, w)$. Obviously, as the upstream firm maximizes profits, in order for $k$ firms to accept the contract, ${ }^{3}$ it will choose $F$ to bind their participation constraint, that is, such that $F=\Pi(k, w)-\Pi_{N}(k-1, w)$. Yet this implies that the problem of choosing the optimal contract $(F, w)$ is equivalent to that of choosing $(k, w)$. Then, in the first stage the dominant upstream firm solves the following problem:

$$
\begin{aligned}
& \quad \operatorname{Max}_{k, w} k\left(\Pi(k, w)-\Pi_{N}(k-1, w)+(w-c) q(k, w)\right) \\
& \text { s.t. } \quad 1 \leq k \leq n \text { and } w \leq c^{\prime} .
\end{aligned}
$$

This problem has been already solved in the literature. Erutku and Richelle (2007) solve an equivalent problem for the case of a research laboratory licensing a cost-reducing innovation to a n-firms homogeneous goods Cournot oligopoly through observable two-part tariff licensing contracts. Making use of this previously existing result, we know first, that regardless of the number of downstream firms, the upstream firm finds it profitable to sell the input to all of them. ${ }^{4}$ Second, if we replace $\mathrm{k}$ by $\mathrm{n}$ and plug the corresponding profit expressions in the maximization problem of the upstream firm we get:

\footnotetext{
${ }^{3} \mathrm{As} \frac{\partial\left(\Pi(k, w)-\Pi_{N}(k-1, w)\right)}{\partial k}<0$, this is the only equilibrium in the acceptance stage.

${ }^{4}$ See the proof of this result in the Appendix.
} 


$$
\operatorname{Max}_{w} \begin{cases}n\left(\left(\frac{a-w}{n+1}\right)^{2}-\left(\frac{a-c^{\prime} n+w(n-1)}{n+1}\right)^{2}+(w-c)\left(\frac{a-w}{n+1}\right)\right) & \text { if } \quad c^{\prime} \geq w \geq \frac{-a+c^{\prime} n}{n-1} \\ n\left(\left(\frac{a-w}{n+1}\right)^{2}+(w-c)\left(\frac{a-w}{n+1}\right)\right) & \text { if } \quad w<\frac{-a+c^{\prime} n}{n-1} .\end{cases}
$$
s.t.w $\leq c^{\prime}$.

Directly solving this problem leads to the following optimal wholesale price:

$$
w^{*}(n)=\frac{(n-1)\left(2 c^{\prime} n+c-a\right)+2 c}{2\left(1-n+n^{2}\right)} \text { if } c^{\prime}<\frac{a-c+(a+c) n^{2}}{2 n^{2}} \text { and } w^{M}(n)=\frac{-a+c+(a+c) n}{2 n} \text { otherwise }^{5} .
$$

The intuition for this result is as follows: concerning the optimality of selling to all firms, we know that with a fixed fee contract, the input would be sold to only a subset of firms in order to protect industry profits from competition (Kamien and Tauman (1986)). With a two-part tariff contract, however, the dominant upstream firm can always sell the input to more firms without affecting the level of competition, by choosing an appropriate (higher) wholesale price. In other words, the dominant firm can always use the wholesale price to control the level of competition downstream. ${ }^{6}$

Concerning the equilibrium contract, note that the maximization program of the dominant supplier can be seen as maximizing total industry profits minus the outside option of downstream firms (that is, what they can get when being supplied by the alternative supplier) and then the optimal wholesale price trades-off two conflicting incentives. On the one hand, maximizing industry profits requires a high wholesale price, while, on the other hand, reducing the outside option of downstream firms needs a low wholesale price. Observe that whenever $c^{\prime} \geq \frac{a-c+(a+c) n^{2}}{2 n^{2}}$,

\footnotetext{
${ }^{5}$ This optimal contract was obtained in Faulí-Oller and Sandonís (2014). They use the same framework to discuss the profitability and welfare effects of downstream mergers.

${ }^{6}$ This argument is also used in Sen and Tauman (2007) to prove that with an auction plus royalty contract, a cost reducing innovation would be sold to all firms by an outsider patentee, and also by Faulí-Oller, González and Sandonís (2014) to show that the same result holds for the case of differentiated goods and for both an outsider and an insider patentee.
} 
the outside option becomes zero and thus the dominant supplier obtains the full monopoly profits. In this case, as $n$ increases the wholesale price is adjusted upwards in order to implement the monopoly price in the final market. On the other hand, it can be checked that $w^{*}$ is an increasing function of $n\left(\frac{d w^{*}(n)}{d n}>0\right)$ and tends to $c^{\prime}$ as $n$ tends to infinity. ${ }^{7}$

We next compute the equilibrium profits of the dominant supplier just by plugging the optimal contract into its profit function. They are given by:

$$
\Pi^{U}(n)=\left\{\begin{array}{cc}
\frac{n\left((a-c)\left((a-c)\left(1+n^{2}\right)-2\left(a-2 c^{\prime}+c\right) n\right)+4\left(a-c^{\prime}\right)\left(c^{\prime}-c\right) n^{3}\right)}{4\left(1+n+n^{3}+n^{4}\right)} & \text { if } c^{\prime} \leq \frac{a-c+(a+c) n^{2}}{2 n^{2}} \\
\left(\frac{a-c}{2}\right)^{2} & \text { otherwise. }
\end{array}\right.
$$

By differentiating the above expression, it is straightforward to get the following result:

Proposition $1 \frac{\partial \Pi^{U}(n)}{\partial n}>0$ if and only if $c^{\prime} \in\left(\widehat{c}(n), \frac{a-c+(a+c) n^{2}}{2 n^{2}}\right)$, where $\widehat{c}(n)=\frac{c(1+n)^{3}+a(n-1)(1+(-4+n) n)}{2 n(4+(n-1) n)}$, and $\widehat{c}(n)<\frac{a+c}{2}$.

We thus find that tougher competition downstream is profitable for the dominant upstream firm whenever the alternative supplier is inefficient enough (or, in other words, when there is strong market power upstream). Let us elaborate further on this result. ${ }^{8}$ As we know, the upstream supplier's problem can be interpreted as choosing the linear wholesale price $w$ that maximizes total industry profits (let us denote them by $\left.\Pi^{I}(w, n)\right)$ minus the sum of downstream firms' outside options (which we denote by $U\left(w, n, c^{\prime}\right)$ ).

Let us define $V\left(n, c^{\prime}\right) \equiv \max _{w}\left[\Pi^{I}(w, n)-U\left(w, n, c^{\prime}\right)\right]$ and denote by $w^{*}\left(n, c^{\prime}\right)$ the solution to this problem. Whether an increase in $n$ raises or lowers $V\left(n, c^{\prime}\right)$ depends on the sign of $\frac{\partial V\left(n, c^{\prime}\right)}{\partial n}$. By using the envelope theorem we can write:

$$
\frac{\partial V\left(n, c^{\prime}\right)}{\partial n}=\frac{\partial \Pi^{I}\left(w^{*}\left(n, c^{\prime}\right), n\right)}{\partial n}-\frac{\partial U\left(w^{*}\left(n, c^{\prime}\right), n, c^{\prime}\right)}{\partial n}
$$

${ }^{7}$ This holds for any $n \geq 2$. Observe that, if $c^{\prime}<\frac{a+3 c}{4}, w^{*}(1)=c>w^{*}(2)$. Note also that the restriction $w \leq c^{\prime}$ is never binding in equilibrium.

${ }^{8}$ We thank an anonymous referee for providing the right intuition for the main result of the paper. 
It is straightforward to check that the first term is negative (stronger competition downstream reduces total industry profits). Therefore, the second term should be negative and large enough as to compensate the first term in order for the complete expression to be positive. However, the second term may be positive or negative depending on the relative efficiency of the alternative supplier. In particular, since $U\left(w, n, c^{\prime}\right)$ represents the sum of the downstream firms' outside options, an increase in $n$ has two opposing effects on $U$. On the one hand, it has a positive direct effect, while on the other hand, it has a negative indirect effect as with more fierce downstream competition, the cost disadvantage of sourcing from the alternative supplier for each downstream firm is magnified (each downstream firm's outside option decreases). It is very intuitive that this negative indirect effect is more significant when the cost disadvantage is large, i.e., $c^{\prime}$ is large. In short, if the alternative supplier is relatively inefficient, the outside options of the downstream firms drop significantly when the number of downstream competitors increases and this effect more than compensates the dominant upstream firm for the decrease in total market profits.

\section{Extensions}

We next discuss whether the above result is robust to the type of contract (two-part tariff versus linear) and to the existence or not of an alternative input supplier. It is easy to show that it is indeed a more general result that holds, for example, in a setting where the upstream firm uses linear wholesale prices no matter whether or not there is an alternative supplier. The reason is that under linear contracts, the optimal wholesale price is constant in the number of downstream firms (see e.g. Petrakis and Dhillon, 2002) and thus, the wholesale revenues of the dominant supplier/ monopolist increase with the number of downstream competitors simply because in a Cournot setting, total output (and so total input demand) increases with the number of firms in the market, thus reducing the double marginalization problem. 
In the following subsection, we show that the main result can also be extended to a linear contract setting where there is (costly) free entry in the downstream market. As we prove next, the dominant supplier finds it profitable to subsidize entry by reducing the wholesale price (compared with the one we would obtain in a setting without entry) in order to encourage the entry of new firms in the downstream industry.

\subsection{Observable linear contracts with free entry}

Assume that we have a monopolist upstream and there is free entry downstream at a fixed cost $K$. In order to study the effect that $w$ has on the equilibrium number of firms in this setting, let us assume that the contract offered by the upstream firm is a long term contract. The equilibrium number of firms in the downstream market for a given $w$ is such that the profits of

downstream firms become zero, that is, such that $\frac{(a-w)^{2}}{(n+1)^{2}}=K$, which gives us $n(w)=\frac{a-w}{\sqrt{K}}-1$ (let us consider for simplicity $n$ as a continuous variable).

In this setting, a change in the wholesale price $w$ has two different effects on the upstream firm's profits. On the one hand, it changes the per-unit upstream revenue; on the other hand, it affects the equilibrium number of downstream firms in the market.

We next write the upstream firm's profits and then replace $n$ by $n(w)$, the equilibrium number of firms:

$\Pi^{U}(w)=n(w)(w-c) \frac{a-w}{(n(w)+1)}=(w-c)\left(\frac{a-w}{\sqrt{K}}-1\right) \sqrt{K}$

Finally, maximizing the previous expression with respect to $w$ we get:

$w^{*}=\frac{a+c-\sqrt{K}}{2}$.

And the equilibrium profits are given by:

$\Pi^{U}\left(w^{*}\right)=\frac{(a-c-\sqrt{K})^{2}}{4}$, which is a decreasing function of $K$.

Summarizing, we can see that a drop in the fixed cost of entry $K$ would increase the upstream 
profits. However, a lower $K$ is also associated with a higher number of firms in the downstream market. In other words, we also obtain in this context a positive relationship between upstream profits and the number of downstream firms. On the other hand, it can be seen that compared with the case of an exogenous $n$, the upstream firm in the model with free entry chooses a lower wholesale price $w$ (it can be directly checked that in the model with linear wholesale prices but with an exogenous $n$, the optimal wholesale price is given by $w^{*}=\frac{a+c}{2}$ ), with the aim to stimulate the entry of new firms in the market.

\section{Conclusions}

This paper has analyzed the relationship between upstream profits and downstream competition. Our main result is that under observable two-part tariff contracts, if we introduce a less efficient alternative input supplier that provides the downstream firms with an outside option, the dominant supplier's profits increase with the number of downstream rivals as long as the alternative supplier is inefficient enough or, in other words, as long as the dominant supplier has sufficiently strong market power upstream. This result has some policy implications. In particular, it implies that the incentives of upstream firms to foreclose downstream firms are less important than the previous literature had suggested. In fact, we have shown that the same result holds under (observable) linear contracts with or without an alternative supplier and also when we consider free entry in the downstream market.

We have derived the main result of the paper assuming that downstream firms produce homogeneous goods and compete in quantities. A possible extension could be to assume that the firms compete in prices (with horizontally differentiated goods). Solving this model explicitly would be complex. ${ }^{9}$ However, it is intuitive to understand that the main qualitative results of

\footnotetext{
${ }^{9}$ To the best of our knowledge, the computation of the optimal two-part tariff contract for a dominant upstream
} 
the present paper would still hold in such a model. Observe that our main result depends on the effect that an increase in the number of downstream firms has on both total industry profits and their outside options. The effect on total industry profits is negative regardless of the type of downstream competition (as long as total industry output is increasing in $n$, which is satisfied by most of the standard competition models) and the double effect on the sum of downstream firms' outside options remains qualitatively similar, namely, there should be a direct positive effect and an indirect negative effect. And again, no matter the type of downstream competition, the latter effect should become larger as the alternative supplier becomes more inefficient (as $c^{\prime}$ increases). This implies that, as in the case of Cournot competition, the natural region to look for a positive effect of downstream competition on upstream firm's profits should still be the region of large $c^{\prime}$ (inefficient enough alternative supplier).

\section{$5 \quad$ References}

Caprice, S., 2005, "Incentive to encourage downstream competition under bilateral oligopoly", Economics Bulletin 12 (9), 1-5.

Chemla, G., 2003, "Downstream competition, foreclosure and vertical integration", Journal of Economics and Management Strategy 12 (2), 261-289.

Erutku, C. and Y. Richelle, 2007, "Optimal licensing contract and the value of a patent", Journal of Economics and Management Strategy 16(2), 407-436.

Faulí-Oller, R., X. González and J. Sandonís, 2013, "Optimal two-part tariff licensing consupplier to sell an input to a differentiated goods Bertrand oligopoly of a general size has not been developed yet in the literature. In particular, it is not clear that the dominant upstream firm would optimally sell the input to all firms in the industry regardless of the number of them. It could well be the case that for a sufficiently high $n$, the dominant upstream firm would prefer not to sell the input to all the downstream firms in order to prevent too much competition in the market. 
tracts with differentiated goods and endogenous R\&D", The Manchester School 81 (5), 803-827.

Faulí-Oller, R. and J. Sandonís, 2014, "Welfare effects of downstream mergers and upstream market concentration", The Singapore Economic Review, forthcoming.

Hart, O. and J. Tirole, 1990, "Vertical integration and market foreclosure", Brookings papers on economic activity. Microeconomics, 205-286.

Kamien, M. and Y. Tauman,1986, "Fees versus royalties and the private value of a patent", The Quarterly Journal of Economics 101, 471-491.

Mathewson, G. F. and R. Winter, 1984, “An Economic Theory of Vertical Restraints", Rand Journal of Economics 15(4), 27-38.

McAfee, R. P. and M. Schwartz, 1994, "Opportunism in Multilateral Vertical Contracting: Nondiscrimination, Exclusivity, and Uniformity", American Economic Review 84(1), 210-230

O'Brien, D. P. and G. Shaffer, 1992, "Vertical Control with Bilateral Contracts", Rand Journal of Economics 23(3), 299-308.

Perry, M. K. and R. H. Porter, 1989, "Can Re-sale Price Maintenance and Franchise Fees Correct Sub-optimal Levels of Retail Service?", International Journal of Industrial Organization $8(1), 115-41$.

Dhillon, A. and E. Petrakis, 2002. "A generalised wage rigidity result," International Journal of Industrial Organization, 20(3), 285-311.

Rey, P. and J. Tirole, 2007, "A Primer on Foreclosure" In Armstrong, M. and Porter, R. (eds) Handbook of Industrial Organization, Vol III, 2145-2220.

Sen, D. and Y. Tauman, 2007, "General licensing schemes for a cost-reducing innovation", Games and Economic Behavior 59 (1), 163-186. 


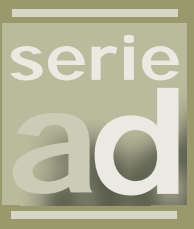

\section{I vie}

Guardia Civil, 22 - Esc. 2, 19

46020 Valencia - Spain

Phone: +34 963190050

Fax: +34 963190055

Website: www.ivie.es

E-mail: publicaciones@ivie.es 